\title{
SOCIEDADE CIVIL E PARTICIPAÇÃO: CONCEPÇÕES HEGEMÔNICAS E CONTRA HEGEMÔNICAS
}

\author{
Emilie Faedo Della Giustina* \\ Danuta Estrufika Cantóia Luiz**
}

\section{INTRODUÇÃO}

Este artigo problematiza teoricamente acerca de duas categorias que permeiam o contexto de manifestação empírica da realidade, bem como as discussões acadêmicas na área das Ciências Sociais, a saber: as possibilidades de significados atribuídos à categoria sociedade civil, bem como à categoria participação.

Apresenta como base referencial, teóricos brasileiros do pensamento gramsciano ${ }^{1}$, os quais nos possibilitam desvendar o "consenso hegemônico" em torno destas expressões que trazem consigo diferenciações de significado e, consequentemente, de intencionalidades. Por isso a importância do esclarecimento sobre as diferentes concepções de sociedade civil e de participação.

Tomemos por pressuposto a concepção gramsciana do que seja o senso comum, exposta em Wanderley (2012, p. 24): o senso comum é um instrumento de dominação de classe, pois a hegemonia relaciona poder e saber. Nesse sentido, “[...] a classe dominante faz com que sua ideologia se popularize, seja incorporada mecanicamente

* Graduada em Serviço Social e aluna do Mestrado em Ciências Sociais Aplicadas da Universidade Estadual de Ponta Grossa - UEPG. Contato: emiliefaedo@hotmail.com

** Doutora em Serviço Social pela Pontifícia Universidade Católica de São Paulo (PUC - SP) e professora do Mestrado em Ciências Sociais Aplicadas na Universidade Estadual de Ponta Grossa (UEPG). Contato: danutaluiz88@gmail.com

${ }^{1}$ Essa sistematização recorre, além da obra do próprio Gramsci, a autores que são referências da tradição gramsciana no Brasil e de reconhecida trajetória acadêmica em relação ao pensamento gramsciano, inclusive tradutores de sua obra para o Brasil, como Carlos Nelson Coutinho (editor da versão em português de Cadernos do Cárcere), Marco Aurélio Nogueira (co-editor da versão em português dos Cadernos do Cárcere), Giovanni Semeraro (autor de Gramsci e a Sociedade Civil, 1999), Ivete Simionatto (autora de Gramsci: sua teoria, incidência no Brasil, influência no Serviço Social, 1995).

Em Tese, Florianópolis, v. 10, n. 1, jan./jun., 2013. ISSN: 1806-5023 
pelo povo, pela falta de uma educação crítica". Conforme argumenta o autor, não significa que não existam verdades no senso comum, mas trata-se de uma concepção equívoca, e tratá-lo como prova de veracidade é um contrassenso.

De acordo com o pensamento gramsciano, a classe dominante busca exercer sua hegemonia também por meio da direção e do consenso, não apenas pela coerção. A concepção de hegemonia está relacionada à socialização do poder, na medida em que a sociedade civil é incorporada à esfera estatal. Simionatto $(2008$, p. 18) argumenta que isso ocorre por meio de diversos mecanismos, mas especialmente pela formação da opinião pública "[...] como estratégia de fortalecimento da hegemonia política por parte do Estado aos assuntos que a ele interessam".

Ou seja, o Estado educa o consenso por meio de aparelhos privados de hegemonia que atuam na criação de um "[...] novo senso comum, do qual são expelidos a política, a participação, a vida em relação aos outros, o sentido de comunidade, o impulso à solidariedade" (LIGUORI apud SIMIONATTO, 2008, p. 18). Nas palavras de Gramsci:

Toda relação de 'hegemonia' é necessariamente uma relação pedagógica, que se verifica não apenas no interior de uma nação, entre as diversas forças que a compõem, mas em todo o campo internacional e mundial, entre conjuntos de civilizações nacionais e continentais (GRAMSCI, 2001, p. 399 - grifo nosso).

Por isso, o Estado é entendido como um complexo de atividades práticas e teóricas a partir das quais a classe dominante justifica e mantém seu domínio, além de obter o consenso dos governados. Disso lê-se que a hegemonia tem sua base no mundo produtivo, ou seja, que a classe dominante é ao mesmo tempo econômica e politicamente dominante.

É no âmbito da sociedade civil que se forma o referido consenso. Nela é que se dão as disputas ente projetos de classe, sendo também o lugar de elaboração da hegemonia. Para o pensamento gramsciano, a hegemonia está relacionada “[...] à efetiva construção democrática que implica a superação entre 'dirigentes' e 'dirigidos', entre 
'governantes' e 'governados"” (SIMIONATTO, 2008, p. 19). Conforme argumenta Gramsci:

Um grupo social pode e, aliás, deve ser dirigente já antes de conquistar o poder (esta é uma das condições principais para a própria conquista do poder); depois, quando exerce o poder e mesmo se o mantém fortemente nas mãos, torna-se dominante mas deve continuar a ser também "dirigente" (GRAMSCI, 2002, p. 62).

De acordo com Campione (2003, p. 52), "[...] os componentes de hegemonia e de coerção coexistem no tempo e no espaço" compondo a supremacia de uma classe que se torna dirigente sem abrir mão do poder coercitivo, ou seja, sem deixar de ser dominante. Com isso, passa a exercer seu domínio para além dos aparatos estatais formalmente reconhecidos, inserindo-se em um espaço social mais amplo. Disso decorre o argumento de que a hegemonia tem múltiplas dimensões e é permeada pela "[...] possibilidade de que se produza uma hegemonia alternativa, ou contra-hegemonia" (CAMPIONE, 2003, p. 52).

A hegemonia não significa, portanto, apenas a subordinação de uma classe em relação à outra, mas contem em si também a possibilidade de transformação da visão de mundo das classes subalternizadas, a elaboração de uma reforma intelectual e moral, em que a "[...] elevação cultural das massas assume importância decisiva neste processo, como instrumento de libertação da pressão ideológica das classes dirigentes", o que significa a superação de uma visão de mundo imposta mecanicamente pela "sociedade oficial" dando lugar a uma direção consciente, por meio da elaboração de uma nova cultura, na formação de uma concepção de mundo crítica e coerente (SIMIONATTO, 2008, p. 24).

Mas o que significa 'cultura' neste caso? Significa indubitavelmente uma coerente, unitária e nacionalmente difundida 'concepção de vida e do homem', uma 'religião laica', uma filosofia que tenha se transformado precisamente em 'cultura', isto é, que tenha gerado uma ética, um modo de viver, uma conduta civil e individual (GRAMSCI, 1968, p. 04 - grifo nosso).

Em Tese, Florianópolis, v. 10, n. 1, jan./jun., 2013. ISSN: 1806-5023 
Chegamos à consideração de que "[...] o Estado moderno retira sua força de - e é protegido por - algo muito mais formidável do que o poder de fogo, a saber, seus poderes e mecanismos de persuasão" (BUTTIGIEG, 2003, p. 46). Sua capacidade de moldar o senso comum, e, por intermédio do consenso, exercer a coerção.

Durante a década de 1990, uma das estratégias para promoção de políticas públicas mais usadas pelos governos brasileiros, principalmente em nível local, foi a aproximação entre sociedade civil e sociedade política. Tatagiba (2006, p. 137) afirma que isto fez da participação um princípio hegemônico, afirmada “[...] acima das intencionalidades dos atores e de suas diferentes filiações político-ideológicas”. O fundamento legal dessas mudanças foi a Constituição de 1988, a qual conferiu aos municípios papel central na gestão das políticas sociais, bem como focalizou a gestão participativa como princípio para elaboração, execução e avaliação das políticas.

Trata-se do resultado de todo um processo de luta da sociedade civil brasileira, que pautaria os caminhos da reforma do Estado e da administração pública no Brasil, contraposto a um passado de centralização, desarticulação, burocratização e autoritarismo, marcas históricas da gestão publica brasileira. Diversos fatores influenciaram essas novas tendências, dentre eles a pressão pela democratização das políticas e as demandas no enfrentamento da pobreza (TATAGIBA, 2006).

O país passa então a vivenciar novos processos de gestão, como os conselhos gestores de políticas públicas, orçamentos participativos, câmaras setoriais, redes, fóruns, e outros espaços públicos construídos no âmbito de programas específicos. Tatagiba (2006) argumenta que as conseqüências dessas experiências para a renovação da gestão local têm gerado interrogações teóricas em torno dos inerentes desafios. Pois, diante do grande aumento dessas iniciativas inovadoras, ainda pouco se sabe "[...] sobre as bases nas quais se dão esses encontros entre sociedade civil e sociedade política, ou ainda quais as tendências resultantes desse processo no que respeita aos significados da democracia em construção" (TATAGIBA, 2006, p. 138). Por isso, avaliar criticamente essas novas experiências de gestão se faz desafiador e necessário, principalmente sob 
um contexto que a autora caracteriza como marcado pela hegemonia do ideário participativo.

Outro termo que traz consigo disputa de significados refere-se à categoria ${ }^{2}$ sociedade civil, razão pela qual, o objetivo deste artigo é, também, trabalhar esta categoria estabelecendo o referencial teórico adotado e articulando três tendências teóricas da sociedade civil existentes na contemporaneidade. Pois conforme argumenta Duriguetto (2007), a generalização do uso deste termo é que coloca a urgência de se conferir uma maior qualificação ao conceito, numa reflexão sobre os diferentes significados e papéis atribuídos à sociedade civil, uma vez que, projetos políticos opostos concebem e fazem uso prático de um mesmo termo, fato que Dagnino (2004) sabiamente denominou de "confluência perversa".

O roteiro para o estabelecimento dessas três tendências teóricas está fundamentado em dois principais autores: Nogueira (2003b) e Simionatto (2010). E, fomentando a discussão, estão Gohn (1997), Dagnino (2004), Duriguetto (2007), Coutinho (1996) e Montaño (2007). Os autores apresentam suas considerações acerca da divergência de significados que a terminologia sociedade civil tem sofrido ao longo dos últimos anos, especialmente a partir da década de 1970, quando essa discussão se aprofunda no cenário nacional, ganhando visibilidade e expressão no senso comum e também na academia.

$\mathrm{Na}$ tentativa de esclarecer as diferenças conceptuais e de conteúdo entre as duas diferentes e antagônicas tradições, a liberal e a marxista, que se fazem presentes como pano de fundo quando usada a categoria sociedade civil, os autores estabelecem nomenclaturas próprias, as quais foram agrupadas neste artigo de acordo com sua significação.

\footnotetext{
${ }^{2}$ Categorias, para Lukács (1979), não são apenas meros conceitos, mas expressam relações, formas de ser, determinações da existência num determinado contexto histórico e social.
} 
Nogueira (2005) bem explicita o porquê de se deixar claro qual significado está sendo atribuído no uso da expressão sociedade civil, pois, como já colocado, tratam-se de significados diferentes que expressam projetos políticos em disputa:

Fala-se em sociedade civil para pensar a oposição ao sistema capitalista e para delinear estratégias de convivência com o mercado, para propor programas democráticos radicais e para legitimar propostas de reforma gerencial no campo das políticas públicas. [...] É em seu nome que se combate a globalização neoliberal e se busca delinear uma estratégia em favor de uma outra globalização, mas é também com base nela que se faz o elogio da atual fase histórica e se minimizam os efeitos das políticas neoliberais. (...) Em suma, o apelo a esta figura conceitual serve tanto para imaginar a autonomia dos cidadãos, quanto para viabilizar programas de ajuste fiscal e desestatização, nos quais se convoca a sociedade civil para compartilhar encargos até então eminentemente estatais (NOGUEIRA, 2005, p. 216).

\section{CONCEPÇÕES TEÓRICAS DE SOCIEDADE CIVIL NA CONTEMPORANEIDADE}

Nos limites deste artigo, a partir da literatura encontrada nos autores já citados há, na contemporaneidade, a mútua convivência entre três principais concepções sobre a categoria sociedade civil: a sociedade civil liberal-democrática, conforme Simionatto (2010) ou sociedade civil social, conforme Nogueira (2003b); a sociedade civil neoliberal (SIMIONATTO, 2010) ou sociedade civil liberal (NOGUEIRA, 2003b); e a concepção gramsciana de sociedade civil (SIMIONATTO, 2010) ou sociedade civil democrático-radical (NOGUEIRA, 2003b) ${ }^{3}$. Apresentamos na sequência uma síntese dessas concepções a fim de esclarecer as diferentes nuances que as compõem.

\footnotetext{
${ }^{3}$ Mantidas as devidas especificações de cada autor, as concepções apresentadas por ambos são muito próximas, razão pela qual fazemos uma aproximação sintética entre as concepções apresentadas pelos autores (os quais possuem em comum referenciais gramscianos em seus estudos). Bem sabemos das muitas correntes teóricas que debatem o tema, desde os clássicos do jusnaturalismo, de Hegel, Rousseau, Marx, mas nosso enfoque neste artigo é o debate contemporâneo que está presente, especialmente, nos dois autores citados.
}

Em Tese, Florianópolis, v. 10, n. 1, jan./jun., 2013. ISSN: 1806-5023 
2.1 Sociedade civil liberal-democrática (SIMIONATTO, 2010)/ Sociedade civil social (NOGUEIRA, 2003b)

Esta concepção de sociedade civil é uma variante da idéia democrático-radical (concepção gramsciana), mas que nem sempre se distingue da sociedade civil liberal, ou ainda, esta concepção esta muito próxima da concepção neoliberal.

Neste caso, a sociedade civil se apresenta como um campo alternativo ao mercado e ao Estado, os personagens que a caracterizam localizam-se na fronteira entre ambos. Há uma recusa em se fazer presente no campo institucional do sistema político por considerar-se maior, superior a ele; toma, pois, uma atitude que é estar "de costas para o Estado" (NOGUEIRA, 2003b, p. 225).

Trata-se dos chamados novos movimentos sociais, os quais concentram suas forças na busca por metas não "materiais" (NOGUEIRA, 2003b, p. 225) mas subjetivas, de cunho moral, como por exemplo, a luta por igualdade de direitos no campo étnico, religioso, cultural, de gênero, etc. Enfim, não dizem respeito ao conflito de classe propriamente dito, embora perpassados por ela, mas a conflitos entre segmentos da sociedade. Ou seja, o tipo de ação social desenvolvida pelo movimento é que o identifica em relação à classe ou camada social em que está situado. Agem no sentido de usar o Estado numa reforma do social, mas com interesses que são fragmentados. E, ao mesmo tempo, estão organizados em redes que extrapolam até mesmo os cenários nacionais que, por meio da chamada cibermilitância, têm ativado a constituição de uma sociedade civil mundial (NOGUEIRA, 2003b; GOHN, 1997).

De acordo com Simionatto (2010, p. 34), esses novos movimentos sociais, embora não mais ligados diretamente à esfera do trabalho e da produção, são tidos “[...] como representantes legítimos dos interesses das classes subalternas" na contemporaneidade.

Em Tese, Florianópolis, v. 10, n. 1, jan./jun., 2013. ISSN: 1806-5023 
Neste cenário, a sociedade civil está situada em um espaço além da sociedade política, do Estado e do mercado, "[...] age-se para contestar o poder e o sistema, mas não para articular capacidades de direção ético-política ou fundar novos Estados" (NOGUEIRA, 2003b, p. 226 e 231). Por isso as ações se fazem quase sempre em rede, sem prever regularidades ou hierarquias organizacionais. $\mathrm{O}$ alvo são os sistemas, mais que os governos propriamente ditos, ou seja, "[...] é um campo de contestação do sistema, mas não de governo do sistema”. Trata-se de um campo de resistência, mas não há nela o potencial de converter essa resistência em ataque, em estratégia de poder, em capacidade de direção.

Conforme Simionatto (2010), uma das principais influências dessa concepção liberal-democrática de sociedade civil é a de Habermas, a qual afasta a centralidade do caráter de classes tão marcante no marxismo e situa a sociedade civil como uma esfera autônoma em relação ao Estado e à economia. Há então, um enfraquecimento de ideais revolucionários e de perspectiva de classe em função de reformas democráticas não direcionadas necessariamente ao Estado.

A sociedade civil é concebida em um momento oposto ao Estado, relacionada a um movimento democratizante que recria formas igualitárias de solidariedade sem, contudo, prejudicar a autorregulação econômica. A autora interpreta que se abstrai da sociedade civil a possibilidade de "[...] disputa pelo poder, a construção de contrahegemonias e de novos Estados" (SIMIONATTO, 2010, p. 36) o que, no entanto, não esvazia dessa concepção seu caráter de resistência ao neoliberalismo, mas que, por outro lado, não considera a sociedade civil como campo de luta política, de disputa pelo poder, para além das conquistas de direitos de cidadania.

Nesta concepção a sociedade civil (mundo da vida) é associada à noção de esfera pública, uma esfera intermediária entre o Estado e o mundo da vida: “[...] Compreendida em uma perspectiva de ampliação da esfera pública, de potencialização e expansão da democracia, pela pluralidade de movimentos auto-organizados" (SIMIONATTO, 2010, p. 35). 
As ações dão-se no sentido de reformas democráticas não direcionadas exclusivamente ao Estado, mas apostando no ativismo da sociedade civil, que tem seu papel político não relacionado diretamente "[...] com o controle ou a conquista do poder, mas com a geração de influência mediante a atividade das associações democráticas" (SIMIONATTO, 2010, p. 36).

Diferencia-se da concepção neoliberal ao passo que se identifica com o fortalecimento de uma esfera pública não estatal de cidadania. “[...] Aproxima-se das formulações liberais em que a sociedade civil é situada como instância autônoma, espaço de articulação de individualidades, atravessada pela neutralidade de classe" (SIMIONATTO, 2010, p. 38).

[...] se o modelo de Estado centrado no neoliberalismo transfere para o mercado questões sociais antes assumidas pelo próprio Estado, e se a função do mercado não é a redistribuição de renda ou a prestação de serviços sociais, recai nas mãos da sociedade civil ou da esfera pública não estatal o encaminhamento de soluções para essa problemática (SIMIONATTO, 2010, p. 37).

Em síntese, esta concepção de sociedade civil liberal/democrática ou sociedade civil social aproxima-se muito do conceito de esfera pública, no entanto, Simionatto (2010) pontua a necessidade do reconhecimento da influência dessa perspectiva nos desenvolvimentos posteriores do conceito, relacionados à perspectiva neoliberal.

\subsection{Sociedade civil neoliberal (SIMIONATTO, 2010)/ Sociedade civil liberal (NOGUEIRA, 2003)}

Da mesma forma, a luta social acontece competitivamente e na esfera privada, sem maiores interferências públicas ou estatais. Não há ações que visem a conquista do Estado, mas ações que são contra o Estado, justamente pelo seu arcabouço teórico estruturante: a concepção liberal de Estado mínimo, ou seja, o Estado é um mal necessário, deve ser mínimo, pois quanto menor, melhor (BOBBIO, 1994).

Em Tese, Florianópolis, v. 10, n. 1, jan./jun., 2013. ISSN: 1806-5023 
Nas palavras de Nogueira (2003b, p. 224), “[...] o Estado que corresponde a esta sociedade civil é um Estado mínimo: um Estado reduzido às funções de guarda da lei e da segurança, mais liberal e representativo que democrático e participativo". A sociedade civil aparece como um espaço que, não somente está fora do Estado, mas contraposto à ele, sem contudo, que haja contestação ao Estado, ou seja, sem a possibilidade de construção de novas hegemonias. "A dinâmica geral não é antisistêmica" (NOGUEIRA, 2003b, p. 229). Produz incentivos que são basicamente competitivos: refragmentação, corporativização, despolitização, pois trata-se do campo da oposição e da concorrência. Nela se articulam movimentos que valorizam interesses particulares, que atendem demandas, fiscalizam governos, desconstroem e desresponsabilizam o Estado, sempre é claro, avançando sobre os fundos públicos, na medida em que se dispõem à prestação de serviços de responsabilidade estatal.

Simionatto (2010) argumenta que a fundamentação dessa concepção de sociedade civil inicia por uma concepção minimizada do Estado, no que tange ao enfrentamento da questão social, somado a um descrédito, veiculado pelo ideário neoliberal, das instituições estatais. Isso tudo afirma uma concepção de sociedade civil pautada na responsabilidade social dos indivíduos e uma participação nos limites da ordem burguesa, respaldada pelo discurso em prol da solidariedade.

A versão mais sofisticada dessa concepção apresenta-se no denominado "terceiro setor" - dominado pelas ONGs mas também integrado por organizações sem fins lucrativos (OSFL), instituições filantrópicas, empresas "cidadãs", fundações, associações comunitárias, movimentos sociais, etc. E que também, mesmo que de forma encoberta, envolve o Estado “[...] ator destacado na promoção do 'terceiro setor', tanto no plano legal quanto na esfera financeira, como contrapartida à retirada paulatina da responsabilidade estatal no trato à "questão social"” (MONTAÑO, 2007, p. 15).

A sociedade civil aparece então, como uma esfera contraposta ao Estado, ou ainda, como uma alternativa ao Estado e ao mercado, um "terceiro setor" que, a partir de uma redução das funções públicas na esfera social, coloca-se de forma contraposta ao 
Estado. No entanto, não impede que este continue sendo o regulador da ordem social e árbitro dos direitos fundamentais: à vida e à propriedade. "Em vez de campo de luta e de conflito, a sociedade civil tornou-se o reino do bem, do voluntariado e da filantropia, contraposto ao Estado considerado como o reino do mal, da ineficiência e da coerção" (COUTINHO apud DURIGUETTO, 2007 p. 12).

Essa leitura segmentada acarreta em consequências ideológicas - funcionais aos interesses do capital no processo de reestruturação neoliberal - de interpretações “[...] desarticuladas da totalidade social, personificando o Estado, o mercado e a sociedade civil, numa clara homogeneização desta última, escamoteando o verdadeiro fenômeno: a desarticulação do padrão de resposta (estatal) às sequelas da 'questão social"" (MONTAÑO, 2007, p. 16).

Ao não se explicitar e não defender o dever do Estado na garantia de direitos sociais retrocede-se

A uma concepção de que o bem-estar pertence ao âmbito do privado, ou seja, as famílias, a comunidade, as instituições religiosas e filantrópicas, devem responsabilizar-se por ele, numa rede de 'solidariedade' que possa proteger os mais pobres (MONTAÑO, 2007, p. 12).

Dagnino (2004) expõe que a relação entre o Estado e o "terceiro setor" (compreendido aqui como sinônimo de sociedade civil) é de transferência de atribuições do primeiro para o segundo. Esta relação, além de produzir poucos resultados positivos, estes são provisórios, fragmentados, pontuais e limitados em relação à diminuição de desigualdades estruturais e melhorias de vida das classes sociais atingidas pelas expressões da questão social. Pois, conforme observa a autora, muitas vezes, há um abandono dos vínculos orgânicos dessas organizações com os movimentos sociais e suas ações acabam por traduzir fundamentalmente os interesses de suas equipes diretivas, acarretando uma fragilidade na representação da sociedade civil como segmento político.

Em Tese, Florianópolis, v. 10, n. 1, jan./jun., 2013. ISSN: 1806-5023 
Nesta concepção tem-se o trabalho voluntário, a responsabilidade social, a solidariedade, promovendo a despolitização da participação, esvaziando o significado político de participação e reduzido-a à gestão das políticas públicas, na busca por legitimidade de governos, diferente da participação tida como partilha do poder entre Estado e sociedade civil.

Quando o:

“[...] Estado se isenta progressivamente de seu papel de garantidor de direitos, o mercado é oferecido como uma instância substituta para a cidadania, há uma "[...] legitimação da concepção do Mercado como instância alternativa de cidadania, na medida em que o mercado se torna a encarnação das virtudes modernas" ${ }^{4}$ (DAGNINO, 2004, p. 106).

O ideário neoliberal fortalece uma concepção homogeneizante e despolitizadora das relações entre Estado e sociedade civil, em que ganham espaço ações sociais mais pontuais, não pautadas na garantia de direitos e desprovidas da possibilidade de “[...] construção de ações em favor de um novo projeto societário". Essas organizações passam então a desempenhar o papel de executoras de políticas públicas, substituindo um espaço de função estatal. Ou seja, a sociedade civil fica

“[...] reduzida ao âmbito dos interesses privados e corporativos, como uma esfera autônoma, destituída da prática política" em que não há mais a disputa pela hegemonia, pois não há o objetivo de construir um novo tipo de Estado (SIMIONATTO, 2010, p. 41 e 46).

\subsection{Concepção gramsciana de sociedade civil (SIMIONATTO, 2010)/ Sociedade civil democrático-radical (NOGUEIRA, 2003b)}

\footnotetext{
${ }^{4}$ Para ilustrar esse deslocamento de significado que sofre a noção de cidadania, e que acaba por afetar a gestão das políticas públicas relacionadas à questão da fome, põe-se em tela a desativação do Conselho de Segurança Alimentar e Nutricional - CONSEA, criado em 1993 com uma forte discussão acerca da questão social e da pobreza, vistas sob a ótica da igualdade e de direitos. Foi desativado para ser substituído por uma proposta do projeto neoliberal que trouxe uma outra forma de gestão social para a questão, a criação do Programa Comunidade Solidária, que trazia em seu bojo um forte apelo à solidariedade e à responsabilidade moral da sociedade, bloqueando a dimensão política envolvida no processo de criação do CONSEA, num entendimento de cidadania restrito à responsabilidade moral privada, a sociedade é chamada a se engajar no trabalho voluntário filantrópico (DAGNINO, 2004).
}

Em Tese, Florianópolis, v. 10, n. 1, jan./jun., 2013. ISSN: 1806-5023 
De acordo com Simionatto (2010), a partir do século XX, e de um intenso processo do que Gramsci irá chamar de socialização da política, há uma maior incorporação dos interesses da classe trabalhadora pelo Estado, e não mais somente o atendimento às demandas da burguesia. Em um movimento dialético de conservação/superação, Gramsci elabora uma nova concepção a respeito do Estado, este agora ampliado, em que se estabelece uma nova relação entre economia e política, entre sociedade civil e sociedade política (GRAMSCI, 2000, p. 254).

Nessa direção, a sociedade civil representa o conjunto de organizações privadas que elabora e/ou difunde ideologias. A relação entre sociedade civil, sociedade política e sociedade econômica não é de distinção orgânica, mas de unidade/negação dialética. Ou seja, tratam-se de categorias interligadas em uma única entidade: o Estado burguêsliberal moderno. Por isso o Estado que corresponde a esta sociedade civil é um Estado social radicalizado, democrático e participativo (NOGUEIRA, 2003b).

Seguindo ainda o pensamento gramsciano, agora exposto em Coutinho (1996), a sociedade civil é formada pelo conjunto de aparelhos privados de hegemonia, ou seja, os grupos e classes sociais, em seu processo de auto-organização e de defesa dos próprios interesses, criam aparelhos privados de hegemonia. Privados porque pressupõe de seus membros uma adesão voluntária, e têm um inegável papel nas relações de poder, na determinação do modo que este se constitui na esfera pública da sociedade. Exercendo assim, influência na determinação das ações do Estado, numa concepção de que Estado e sociedade civil não estão em oposições dicotômicas, mas, articulam-se dialeticamente.

Conforme frisa Nogueira (2003a), a sociedade civil não é um mero terreno de iniciativas privadas, mas tem uma função estatal, tornando-se uma espécie de “dimensão civil" do Estado, a sede de múltiplos organismos privados, mas nem por isso, menos estatais. A sociedade civil gramsciana não se sustenta fora do campo do 
Estado, muito menos em oposição dicotômica a ele, mas articula-se dialeticamente no Estado e com o Estado.

O autor argumenta que Gramsci pensava numa sociedade civil que se poderia chamar de sociedade civil político-estatal, a qual é o campo da contestação política, socialmente vinculado ao governo, e apresenta maior capacidade de processar, articular demandas e interferir na vida coletiva.

\begin{abstract}
Nessa concepção, portanto, a sociedade civil é considerada um espaço onde são elaborados e viabilizados projetos globais de sociedade, se articulam capacidades de direção ético-política, se disputa o poder e a dominação. Um espaço de invenção e organização de novos Estados e novas pessoas. Um espaço de luta, governo e contestação, no qual se formam vontades coletivas (NOGUEIRA, 2003a, p. 191).
\end{abstract}

Há que considerar que, dentro desta concepção, a sociedade civil não é um campo neutro, mas uma esfera heterogênea e de intensa correlação de forças na disputa por diferentes projetos, pois, não se restringe à luta por direitos sociais, mas, para além disso, insere-se na luta entre projetos societários.

Vale lembrar que a sociedade civil não é um campo universal, organizada exclusivamente por valores civilizados, como uma extensão mecânica da vida democrática, mas também é perpassada por interesses que se contrapõem e que podem até se desenvolver em atitudes incivis (NOGUEIRA, 2003b).

Por fim, de acordo com Duriguetto (2007), a sociedade civil gramsciana é a esfera em que as classes organizam e defendem seus interesses e disputam a hegemonia. Enquanto a sociedade política corresponde ao conjunto de aparelhos através dos quais a classe dominante impõe coercitivamente sua dominação. Em conjunto, essas duas esferas, sociedade civil e sociedade política, formam o Estado. Na famosa formulação de que: "Estado $=$ sociedade política + sociedade civil (hegemonia couraçada de coerção)" (GRAMSCI, 2000, p. 254). A sociedade civil gramsciana faz parte do Estado.

Sua defesa da estratégia revolucionária ocidental está concentrada na "guerra de posição", ou seja, conquistas progressivas de espaços de direção político-ideológica e de

Em Tese, Florianópolis, v. 10, n. 1, jan./jun., 2013. ISSN: 1806-5023 
formação de um consenso organizado e participativo no campo da sociedade civil. Tendo em vista que, a obtenção da hegemonia deve preceder a tomada do poder, por um processo progressivo de democratização, numa relação orgânica entre hegemonia e democracia.

Duriguetto (2007, p. 67) esclarece que “[...] é no campo da ideologia que se opera a passagem dos interesses grupais aos universais. [...] A sociedade civil é o domínio da ideologia, é a esfera em que se desenvolve a luta pela hegemonia”. Ou seja, a sociedade civil é um momento da superestrutura, o momento da hegemonia, compreendendo, além das relações materiais, o complexo das relações ideológicoculturais, participando assim, da elaboração das ideologias e das técnicas do consenso (BOBBIO, 1994).

De acordo com Nogueira (2003b), esta idéia de sociedade civil ainda não é a hegemônica, ainda não tem a capacidade de direção. A ela estão contrapostas outras duas ideias apresentadas anteriormente que se fazem hegemônicas em função do ideário neoliberal e de suas prerrogativas de enxugamento do Estado: a sociedade civil liberal ou neoliberal e a sociedade civil social ou liberal-democrática. $\mathrm{O}$ autor frisa que

[...] em Gramsci, sociedade civil é um conceito, complexo e sofisticado, com o qual se pode entender a realidade contemporânea. Mas é também um projeto político, abrangente e igualmente sofisticado, com o qual se pode transformar a realidade (NOGUEIRA, 2003b, p. 219).

Vale lembrar que,

Todas estas três idéias de sociedade civil cabem na realidade contemporânea. Na verdade, espelham esta realidade e tentam ao mesmo tempo direcioná-la: trazem consigo correspondentes projetos políticos e idéias de Estado. Em boa medida, oscilamos e vivemos prensados entre estas três idéias, sentindo os efeitos e os reflexos delas (NOGUEIRA, 2003b, p. 227 - grifo nosso).

Ressaltamos que o uso da categoria sociedade civil não se trata apenas de um instrumento de análise, mas, sobretudo, de um instrumento de projeto sócio-político, na

Em Tese, Florianópolis, v. 10, n. 1, jan./jun., 2013. ISSN: 1806-5023 
construção de uma contra-hegemonia na disputa do poder pelas classes subalternas, visando a socialização do poder político e da riqueza socialmente produzida. Ou seja, mais do que um método de estudo da realidade, trata-se de uma proposta de transformação desta (NOGUEIRA, 2003).

\title{
3 A HEGEMONIA DO IDEÁRIO PARTICIPACIONISTA ${ }^{5}$
}

Uma das categorias que materializa as diferentes concepções de sociedade civil é a participação. Intrinsecamente relacionada à primeira, a participação também é permeada pelos determinantes ideo-sócio-politicos que a modelam e/ou a diferenciam. Portanto, esta categoria, como um fenômeno político-social, compõe processos hegemônicos e também, os contra-hegemônicos.

Com este pressuposto, identifica-se que nas últimas duas décadas do século $\mathrm{XX}$ houve uma "[...] afirmação categórica da ideia de participação no campo da gestão pública" (NOGUEIRA, 2005, p. 117), ocorrendo uma espécie de inversão da hipótese decisionista que predominara em momentos imediatamente anteriores, em que

\begin{abstract}
A concepção de que processos participativos não colaboravam para o crescimento econômico, pois dificultavam a tomada rápida de decisões foi sendo, pouco a pouco, substituída pelo reconhecimento de que a participação tem um valor em si, e, além disto, potencialmente 'relevante no fornecimento de sustentabilidade às políticas públicas e ao próprio desenvolvimento. Os processos participativos converteramse, assim, em recurso estratégico do desenvolvimento sustentável e da formulação de políticas públicas, particularmente na área social' (NOGUEIRA, 2005, p. 118).
\end{abstract}

\footnotetext{
${ }^{5}$ Sem desconsiderar outros autores como Gohn, Scheren-Warren, Dagnino, Duriguetto, Montaño, dentre outros, neste item estão sistematizados dois autores referenciais no debate sobre a participação da sociedade civil em suas diversas dimensões da vida social: Tatagiba (2006) e Nogueira (2005).
}

Em Tese, Florianópolis, v. 10, n. 1, jan./jun., 2013. ISSN: 1806-5023 
Nesse sentido, Tatagiba (2006) aponta que, a partir da década de 1990, há uma ressignificação da prática participativa no cenário brasileiro. Ou seja, apesar do consenso estabelecido no período em torno do ideário participacionista, o que ocorre é uma diversificação dos fundamentos normativos que historicamente legitimaram a participação. Tendo em vista que, nos anos de 1970 e 1980, a participação se dava em torno de ações contestatórias, associadas à utopias transformadoras e, na década de 1990 entra em cena um novo fundamento do ideário participacionista. Conforme argumenta a autora:

O tema da participação, no bojo da luta pela redemocratização do Estado brasileiro, traz consigo uma forte carga normativa, cujo horizonte desejável esteve historicamente associado à transformação, entendida como alteração completa ou parcial das estruturas de dominação (TATAGIBA, 2006, p. 141).

No entanto, a partir dos anos de 1990 surge a disputa por uma nova significação das experiências participativas, a qual tem como fonte de legitimidade a expectativa por uma gestão pública mais eficaz. A participação aparece então, revestida de um novo conjunto de valores, visando o aumento da eficiência e eficácia das políticas implementadas, principalmente na área social. É revestida de um caráter de "ferramenta de gestão" sintonizando a administração pública com o novo tempo da sociedade globalizada, complexa e que "[...] exige a superação das formas convencionais, burocráticas e hierárquicas de gestão" (TATAGIBA, 2006, p. 141).

Soma-se à legitimidade política e de caráter moral da participação, a legitimidade macroeconômica e gerencial, ou seja, a participação passa a ser percebida como uma alternativa de gestão mais eficiente que as tradicionalmente utilizadas nas políticas públicas, como por exemplo, os modelos burocráticos e os paternalistas (TATAGIBA, 2006). 
A participação da sociedade civil adquire caráter de "parceria" com o Estado, ampliando a capacidade de intervenção do governo, potencializando os recursos existentes e criando condições de sustentabilidade de programas e projetos. Tudo isso em meio a um contexto de redução do papel do Estado e mais, a motivação de contestação que caracterizava o discurso participacionista "[...] se dissolve no discurso técnico e supostamente neutro da moderna gerência, num evidente deslocamento do tema do conflito em favor da temática da eficiência e eficácia das políticas" (TATAGIBA, 2006, p. 142).

Tem-se, portanto, que a legitimação da participação constrói-se sobre esses distintos fundamentos os quais não apenas convivem lado a lado mas também estruturam a disputa de significados quanto à natureza da democracia em construção. Ou seja, o confronto e oposição que caracterizavam as relações entre Estado e sociedade civil no período da resistência contra a ditadura, cedem lugar para uma postura de negociação, aberta a uma atuação conjunta sob o estigma da participação da sociedade civil.

Disso depura-se que, assim com a sociedade civil tem diferentes concepções e direções, a categoria participação também, e, por consequência, possuem diferentes matizes e intenções. Nogueira (2005, p. 130) elabora um roteiro contendo quatro grandes modalidades de participação, as quais coexistem e se combinam de diferentes maneiras. "Tais modalidades expressam, também, os diferentes graus de consciência política coletiva, correspondendo, assim, à maior ou menor maturidade, homogeneidade e organicidade dos grupos sociais". São elas:

1. Participação Assistencialista: de natureza filantrópica ou solidária, como, por exemplo, práticas de auxílio mútuo e de mutirão. Nas fases que precederam à afirmação dos direitos de cidadania, foi essa a modalidade dominante de participação. Ela também tende a predominar nos estágios de menor maturidade e organicidade dos grupos sociais ou de menor consciência política coletiva.

Em Tese, Florianópolis, v. 10, n. 1, jan./jun., 2013. ISSN: 1806-5023 
2. Participação corporativa: dedicada à defesa de interesses específicos de determinados grupos sociais ou de categorias profissionais. Trata-se de uma participação fechada em si, ganham apenas os que pertencem ao grupo ou à associação. Foi essa participação que esteve na origem do sindicalismo moderno. Tanto quanto a participação assistencialista, esta é uma modalidade universal de participação.

"Ambas, aliás, interpenetram-se intensamente, até mesmo porque estão articuladas de maneira estreita com problemas existenciais imediatos, práticos, concretos, quase sempre de fundo econômico" (NOGUEIRA, 2005, p. 135).

O autor argumenta que essas duas modalidades de participação integram uma espécie de dimensão pré-política da agregação moderna, mas nem por isso irrelevante, negativa ou inferior, que são práticas muito mais relacionadas ao proletariado e às camadas populares que à burguesia.

3. Participação eleitoral: esta modalidade de participação insere-se no campo político propriamente dito. Não visa apenas a defesa de interesses particulares, mas interfere diretamente na governabilidade e tem efeitos que dizem respeito a toda a coletividade. Aqui o cidadão está muito mais maduro, afirmando-se não apenas em relação a si próprio, mas também em relação aos outros. Tem, porém, seus limites, pois não necessariamente leva a uma reorganização do Estado ou do poder político (NOGUEIRA, 2005). Na atual organização do regime político brasileiro, organiza-se pelo voto de representantes políticos para o exercício do poder democrático.

4. Participação política: "[...] inclui, complementa e supera tanto a participação eleitoral, quanto a participação corporativa. Não colide com elas, nem as rejeita como algo 'menor', muito pelo contrário", apenas diferencia-se. Realiza-se tendo em vista a comunidade como um todo, a organização da vida social em seu conjunto, ou seja, o Estado. "É uma prática ético-política, que tem a ver tanto com a questão do poder e da dominação quanto com a questão do consenso e da hegemonia, tanto com a força

Em Tese, Florianópolis, v. 10, n. 1, jan./jun., 2013. ISSN: 1806-5023 
quanto com o consentimento". É mediante a participação política que a vontade geral se objetiva, que indivíduos e grupos interferem na explicitação de suas demandas, fazendo com que o poder se democratize e seja compartilhado (NOGUEIRA, 2005, p. 133). Podemos citar como exemplos de espaços institucionalizados com fins à participação política os conselhos e as conferências de políticas públicas.

Devido ao fato desta diferenciação estar presente tanto no interior do Estado quanto no interior da sociedade civil é que "[...] a questão da participação da sociedade civil é um elemento fundamental de diferenciação entre os vários projetos políticos em disputa" (TATAGIBA, 2006, p. 142), entre a hegemonia e a contra hegemonia. Por isso, este consenso (modelado pela coerção) em torno do ideário participacionista escamoteia distintos projetos e intenções políticas, os quais são orientados por diferentes concepções acerca do que seja a sociedade civil, a participação, e também a democracia. Todas estas categorias compõem a concepção democrático participativa, na qual os valores, interesses e projetos conflitantes devem ser levados para processos deliberativos a fim de potencializar a mútua crítica e o aprendizado reflexivo.

Já para a perspectiva da democracia gerencial, há a tentativa de combinar a participação com a despolitização do debate público, por meio do monopólio das decisões nas mãos do Estado "[...] combinando, desta forma, a ampliação da participação com um estilo de gestão tecnocrático" (TATAGIBA, 2006, p. 145). Por isso é que, nos marcos da democracia gerencial, a participação perde seu potencial transformador/de luta contra-hegemônica e volta-se à execução das políticas públicas, revestida de apatia política em relação ao debate das escolhas políticas.

Ou, dito de outra forma, um dos principais desafios da democracia gerencial parece ser combinar participação política com uma democracia de baixa intensidade (...) o que está em jogo não é a mudança das condições de dominação, mas a possibilidade de administrar de forma eficiente os recursos financeiros, materiais e humanos existentes. O que se busca, como horizonte de expectativas, não é a partilha do poder de governar, mas a dissolução desse poder na gerência eficiente (TATAGIBA, 2006, p. 145). 


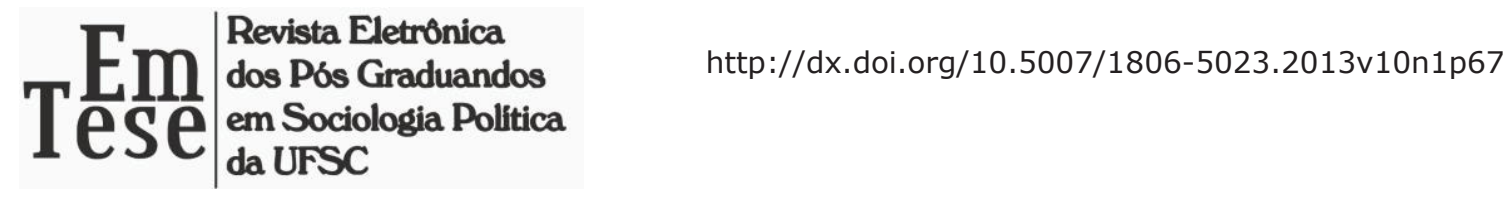

Nesse sentido, a tendência de instrumentalização da prática participativa se dá com o fim de produzir políticas eficientes de combate à pobreza, num contexto contraditório de redução de instrumentos públicos na área social em que a participação assume um caráter instrumental, contribuindo para a manutenção da configuração histórica da sociedade brasileira.

Percebe-se, portanto, que o tema da participação traz em si um forte conteúdo ideológico, possibilitando diferentes concepções e manifestações na vida prática, as quais trazem consigo seus respectivos projetos societários. Embora o ideário a favor da participação se manifeste de maneira consensual, trazendo aqui o entendimento de que o consenso é estabelecido pela hegemonia (ou seja, pela capacidade de direção da classe dominante) e justamente por isso é também fruto da coerção, o debate teórico a respeito dessas categorias se faz necessário para um entendimento mais profundo desses processos participativos adensados a partir da Constituição de 1988.

\section{CONSIDERAÇÕES FINAIS}

Este artigo teve por finalidade explicitar as nuances em torno da categoria sociedade civil, a qual, assim como a categoria participação, traz em torno de si um uso generalizado que precisa desvendar sua intencionalidade, uma vez que, conforme argumentado anteriormente, diferentes projetos políticos e societários abrigam-se como pano de fundo de mesmas expressões.

Nas considerações finais deste artigo não poderíamos nos furtar das contribuições feitas pelos dois principais autores que fundamentaram a síntese aqui produzida: Nogueira e Simionatto. No sentido da definição de um posicionamento sobre qual ou quais perspectivas devemos ter como norte sobre as categorias aqui discutidas.

Diante do direcionamento hegemônico sobre o que seja a participação da sociedade civil nas políticas públicas, Nogueira $(2005$, p. 57$)$ ressalta que

Em Tese, Florianópolis, v. 10, n. 1, jan./jun., 2013. ISSN: 1806-5023 
Participação e sociedade civil não mais serão vistas como expressão e veículo da predisposição coletiva para organizar novas formas de Estado e de comunidade política, de hegemonia e de distribuição do poder, mas sim como a tradução concreta da consciência benemérita dos cidadãos, dos grupos organizados, das empresas e das associações.

No sentido de contrapor esta tendência, considera-se que, para avançar em processos democráticos que elevem a concepção de sociedade civil democrático radical, e consequentemente de participação política, é que se coloca

[...] efetivamente a questão da sociedade civil. Fora daí, ela não faz muito sentido, ou, o que dá no mesmo, tem um sentido estrito e limitado. Isso quer dizer que precisamos de uma perspectiva que não só valorize a sociedade civil e celebre seu crescente protagonismo, mas também colabore para politizá-la, libertando-a das amarras reducionistas e repressivas dos interesses particulares, aproximando-a do universo mais rico e generoso dos interesses gerais, da hegemonia, em uma palavra, do Estado (NOGUEIRA, 2005, p. 102).

Para marcar posição em defesa desta perspectiva, este artigo trouxe à tona a discussão acerca dos desafios e ambiguidades inerentes à participação da sociedade civil, num contexto de hegemonia do ideário participacionista, demonstrando que, muitas vezes, a participação pode compor uma estratégia de despolitização do debate público e promoção da apatia política, por meio da qual se consolida uma democracia de baixa intensidade. Esta perspectiva alia-se à concepção neoliberal de sociedade civil, a qual se manifesta em contraposição ao Estado, sem, contudo, que haja contestação ou socialização do poder, ou seja, sem a intenção de construção de uma contra-hegemonia.

As novas objetivações do capitalismo moderno induzem a uma participação que é desvinculada de um conteúdo ético-político, vinculando-se mais estreitamente a interesses particulares, direcionados à resolução de demandas específicas. Tende a converter-se em instrumento para agilizar a ação governamental e reduzir atritos entre governos e sociedades, concentrada muito mais na "[...] obtenção de vantagens e

Em Tese, Florianópolis, v. 10, n. 1, jan./jun., 2013. ISSN: 1806-5023 
resultados do que na modificação de correlações de forças ou de padrões estruturais" (NOGUEIRA, 2005, p. 142).

Por isso, “[...] este 'deslizamento semântico' inverteu e modificou o sentido e o valor de alguns estratégicos conceitos democráticos" (NOGUEIRA, 2005, p. 55). Num âmbito em que as organizações da sociedade civil que se fazem representar nos aparatos participativos institucionalizados irão se dirigir muito mais para a gestão de políticas do que para a configuração de um debate público-político a respeito do que seja a sociedade civil e a participação e as suas reais atribuições numa perspectiva críticoradical.

No sentido de reiterar uma direção que nos parece ética e politicamente comprometida com valores contra-hegemônicos, finalizamos a argumentação aqui traçada com as palavras de Simionatto:

A concepção de sociedade civil em Gramsci [...] permite superar sua identificação com o conceito de terceiro setor (ONGs, voluntariado, filantropia) visto que é atravessada pela perspectiva de totalidade e unidade entre as esferas política e econômica, cultural e política, compreendidas em seu processo dialético e contraditório. Além disso, a categoria sociedade civil no pensamento gramsciano não se restringe à luta pela cidadania e pelos direitos sociais, embora esta represente um momento de mediação fundamental da práxis política. Não se configura somente como 'o espaço da razão discursiva' ou do debate democrático, 'mas o confronto de projetos societários, cujo horizonte, para as classes subalternas, é o da socialização do poder político e da riqueza socialmente produzida' (Durighetto, 2007, p.224). O marco conceitual de Gramsci definitivamente não é o agir comunicativo, nem tampouco a perspectiva neoliberal, que reduz a sociedade civil ao mercado, oposta ao Estado e à política em sentido amplo. Há na concepção gramsciana de sociedade civil 'um caráter radicalmente classista' (Durighetto, 2006, p.124), uma dimensão nitidamente política, [...] o que remete à luta pela hegemonia e à conquista do poder pelas classes subalternas (Coutinho, 2008). [...] A sociedade civil definida por Gramsci (2000, p.225) significa, assim, 'a hegemonia política e cultural de um grupo social sobre toda a sociedade, como conteúdo ético do Estado'. (SIMIONATTO, 2010, p. 51).

Em Tese, Florianópolis, v. 10, n. 1, jan./jun., 2013. ISSN: 1806-5023 
Portanto, desvelar estas diferentes concepções é importante para, a partir deste empreendimento, fortalecer uma concepção crítica a respeito da socialização do poder político e da riqueza socialmente produzida, caminhando para a construção de uma contra-hegemonia ao ideário neoliberal a respeito destas categorias teórico/práticas que se relacionam intrinsecamente: sociedade civil e participação.

\section{REFERÊNCIAS}

BUTTIGiEG, J. A. Educação e hegemonia. In: COUTINHO, C. N. TEIXEIRA, A. P. Ler Gramsci, entender a realidade. Rio de Janeiro: Civilização brasileira, 2003

BOBBIO, N. (et al). Dicionário de Política. $6^{\circ}$ Ed. Brasília: Editora Universidade de Brasília. Verbete Sociedade Civil. 1994

COUTINHO, C. N. Marxismo e Política: a dualidade de poderes e outros ensaios. São Paulo:Cortez, 1996.

CAMPIONE, D. Hegemonia e contra-hegemonia na América Latina. In: COUTINHO, C. N. TEIXEIRA, A. P. Ler Gramsci, entender a realidade. Rio de Janeiro: Civilização brasileira, 2003.

DAGNINO, E. “¿Sociedade civil, participação e cidadania: de que estamos falando?” In MATO, Daniel (coord.). Politicas de ciudadanía y sociedad civil en tiempos de globalización. Caracas: FACES, Universidad Central de Venezuela, pp. 95-110, 2004.

DURIGUETTO, M. L. Sociedade civil e democracia: um debate necessário. São Paulo: Cortez, 2007.

GOHN, M. da G. Teoria dos Movimentos Sociais: Paradigmas clássicos e contemporâneos. São Paulo: Edições Loyola, 1997.

GRAMSCI, A. Cadernos do Cárcere. Vol. 2. Rio de Janeiro: Civilização Brasileira, 2000.

GRAMSCI, A. Cadernos do Cárcere. Vol. 1. Rio de Janeiro: Civilização Brasileira, 2001.

Em Tese, Florianópolis, v. 10, n. 1, jan./jun., 2013. ISSN: 1806-5023 
GRAMSCI, A. Cadernos do Cárcere. Vol. 5. Rio de Janeiro: Civilização Brasileira, 2002.

LUKÁCS, G. Ontologia do ser social: os princípios ontológicos fundamentais de Marx. São Paulo : Ciências Humanas, 1979.

MONTAÑO, C. Terceiro setor e questão social: crítica ao padrão emergente de intervenção social. 4. ed. São Paulo: Cortez, 2007.

NOGUEIRA, M. A. Sociedade civil, entre o político-estatal e o universo gerencial. In: Revista Brasileira de Ciências Sociais. Vol. 18, n 52 jun/2003a.

NOGUEIRA. M. A. As três idéias de sociedade civil, o Estado e a politização. In: COUTINHO, C. N. TEIXEIRA, A. P. Ler Gramsci, entender a realidade. Rio de Janeiro: Civilização brasileira, 2003 b.

NOGUEIRA, M. A. Um Estado para a sociedade civil: temas éticos e políticos da gestão democrática. 2 ed. - São Paulo: Cortez, 2005.

SIMIONATTO, I. Razões para continuar utilizando a categoria sociedade civil. In: LUIZ, D. E. C. (org.). Sociedade Civil e Democracia: expressões contemporâneas. São Paulo: Veras, 2010.

SIMIONATTO, I. Gramsci: sua teoria, incidência no Brasil, influência no Serviço Social, Florianópolis: Cortez, 1995

TATAGIBA, L. Os desafios da articulação entre Sociedade Civil e Sociedade Política sob o marco da democracia gerencial. O caso do Projeto Rede Criança em Vitória/ES. In: DANINO, E. OLVERA, A. J. e PANFICHI, A. (orgs.). A disputa pela construção democrática na América Latina. São Paulo: Paz e Terra; Campinas, SP: Unicamp, 2006.

WANDERLEY, L. E. W. Sociedade civil e Gramsci: desafios teóricos e práticos. In: Revista Serviço Social \& Sociedade. São Paulo, n. 109, 2012.

\section{SOCIEDADE CIVIL E PARTICIPAÇÃO: CONCEPÇÕES HEGEMÔNICAS E CONTRA HEGEMÔNICAS}




\title{
RESUMO
}

Este artigo tem por finalidade discutir, a partir de revisão de literatura, duas categorias: sociedade civil e participação. Tendo em vista que a discussão sobre essas duas categorias teóricas se faz imprescindível para qualquer estudo que se pretenda no âmbito da elaboração, implementação e controle de políticas públicas, principalmente as políticas sociais. Especialmente porque, nas últimas décadas, o uso dessas duas expressões generalizou-se e tornou-se um "consenso hegemônico" que abriga em seu interior diferenciações fundamentais as quais, se não analisadas de perto, podem confundir-se. Por isso a importância do debate sobre diferentes concepções de sociedade civil e de participação.

PALAVRAS-CHAVE: Sociedade Civil. Participação. Hegemonia. Contra Hegemonia.

\section{CIVIL SOCIETY AND PARTICIPATION: HEGEMONIC CONCEPTIONS AND COUNTER-HEGEMONIC}

\begin{abstract}
This article has as finality discuss from a literature review, still in a short way, two categories: civil society and participation. Taking into account that the discussion of these two theoretical categories makes itself indispensable for every study on elaboration, implementation and control of public policies, especially the social policies. Moreover, on last decades, the use of these two expressions took a generalization and became a "hegemonic consensus" which contains inside fundamental differences which, if not analyzed very close, can get confused themselves. That's why the value of the clarification about the different conceptions of civil society and participation.
\end{abstract}

KEY-WORDS: Civil Society. Participation. Hegemonic. Counter-Hegemonic.

Recebido em: 3 de setembro de 2012

Aceito para publicação: 18 de março de 2014

Em Tese, Florianópolis, v. 10, n. 1, jan./jun., 2013. ISSN: 1806-5023 